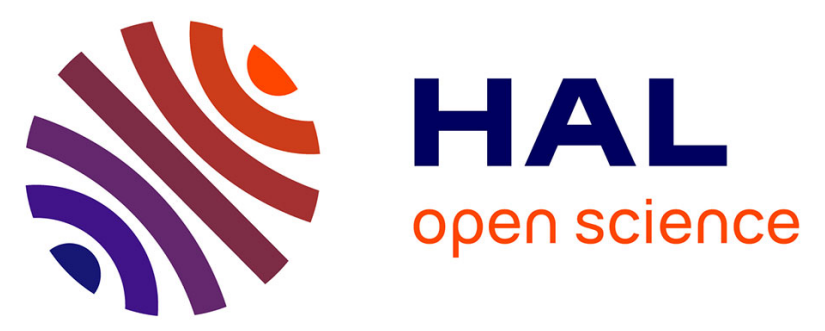

\title{
Combined use of lifecycle management and IoT in smart cities
}

\author{
Ahmed Hefnawy, Taha Elhariri, Chantal Cherifi, Abdelaziz A Bouras, Jérémy \\ Robert, Sylvain Kubler, Kary Fr mling
}

\section{To cite this version:}

Ahmed Hefnawy, Taha Elhariri, Chantal Cherifi, Abdelaziz A Bouras, Jérémy Robert, et al.. Combined use of lifecycle management and IoT in smart cities. 11th International Conference on Software, Knowledge, Information Management \& Applications, SKIMA 2017, Dec 2017, Colombo, Sri Lanka. 10.1109/SKIMA.2017.8294112 . hal-02444880

\section{HAL Id: hal-02444880 \\ https://hal.science/hal-02444880}

Submitted on 19 Jan 2020

HAL is a multi-disciplinary open access archive for the deposit and dissemination of scientific research documents, whether they are published or not. The documents may come from teaching and research institutions in France or abroad, or from public or private research centers.
L'archive ouverte pluridisciplinaire HAL, est destinée au dépôt et à la diffusion de documents scientifiques de niveau recherche, publiés ou non, émanant des établissements d'enseignement et de recherche français ou étrangers, des laboratoires publics ou privés. 
See discussions, stats, and author profiles for this publication at: https://www.researchgate.net/publication/323281449

\section{Combined use of lifecycle management and IoT in smart cities}

Conference Paper · December 2017

DOI: 10.1109/SKIMA.2017.8294112

CITATION

1

7 authors, including:

2. Ahmed Hefnawy

(d) Université Lumiere Lyon 2

12 PUBLICATIONS 84 CITATIONS

SEE PROFILE

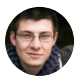

Jérémy Robert

University of Luxembourg

37 PUBLICATIONS 301 CITATIONS

SEE PROFILE

Some of the authors of this publication are also working on these related projects:

bloTope View project

COMPLEX NETWORKS View project
53 PUBLICATIONS 155 CITATIONS

SEE PROFILE 


\section{Combined Use of Lifecycle Management and IoT in Smart Cities}

\author{
Ahmed Hefnawy, Taha Elhariri, Chantal Cherifi \\ DISP Lab. \\ Université Lumière Lyon 2 \\ Lyon, France
}

\author{
Abdelaziz Bouras \\ DCSE, College of Engineering \\ Qatar University \\ Doha, Qatar
}

\author{
Jérémy Robert \\ Interdisciplinary Centre for Security, Reliability and Trust \\ University of Luxembourg \\ Luxembourg \\ Sylvain Kubler \\ Université de Lorraine, CRAN, UMR 7039, Campus \\ Sciences, BP 70239, Vandoeuvre-lès-Nancy F-54506 \\ CNRS, CRAN, UMR 7039, France
}

\author{
Kary Främling \\ Aalto School of Science and Technology \\ Aalto University \\ Finland
}

\begin{abstract}
IoT-enabled smart city service systems are well recognized to address issues of urbanization in the city environment. In most cases, those systems are vertically locked; and from lifecycle perspective, independently designed, built and operated. Therefore, there is a need for a global vision to horizontally integrate those systems to ensure smooth flow of information across different domains. To ensure interoperability and better management across different phases of smart city lifecycle, this paper highlights the need for smooth exchange of two types of data/ information: (i) generated data from IoT data sources; (ii) lifecycle system related information. This paper proposes the use of The Open Group IoT standards to ensure interoperability and smooth data exchange; and the use of lifecycle management system to create Bill of Materials; export Objects' Tree and exchange lifecycle system related information. It also demonstrates the interaction between the proposed lifecycle system and IoT platform within smart parking use-case.
\end{abstract}

Keywords - Internet of Things; Smart City; Smart Parking; Interoperability; Lifecycle Management.

\section{INTRODUCTION}

Internet of Things (IoT) exists in the smart city environment in many forms. The simplest form of IoT is the form of single objects, like sensors and actuators that collect data and execute commands respectively. IoT can also exist in the form of stand-alone systems that address domain-specific issues, like transportation, parking, energy, lightening, etc. The form that benefit cities more is the form of interconnected systems. In such form, cities are smarter by having valuable information, prior knowledge and cross-sectorial decisions smoothly exchanged between different domains.

To ensure data exchange between different IoT objects and systems, several standardization organizations have addressed interoperability in IoT through multiple initiatives, like the IEEE Internet of Things (IoT) initiative [1]; the Alliance for Internet of Things Innovation (AIOTI) [2]; the Web of Things initiative at $\mathrm{W} 3 \mathrm{C}$ [3]; the OneM2M global standards initiative [4]; and, the Open Platform 3.0TM initiative at The Open Group that aims to rely on open standards [5]. Although most of those initiatives promote various types of standards and specific technology enablers, they all share the same vision about relying as much as possible on open and interoperable standards to foster open ecosystems and unlock the commercial potential of IoT.

Although these initiatives have led to multiple initial IoT platforms, it is a great challenge to turn those IoT platforms into economically viable entities and ecosystems; and, to manage the relationships between different platforms in an integrated way. The challenge is multifold in case of IoT smart city applications, in light of diversity of application domains, heterogeneity of data sources, big number of stakeholders and interdependency between different smart systems. For this, it has been proposed in [6] to manage IoT-enabled smart cities using lifecycle management principles to better integrate people, processes, and systems across different phases of lifecycle. Hence, there is a need for two types of data to be exchanged. First, data collected from heterogeneous IoT data sources that can be used in different domains. Second, system data, versions, variants, processes and other lifecycle related data.

The problem that this paper addresses is that the two types of data are exchanged over two different platforms, namely IoT platform and lifecycle management system. This paper addresses the question of how to integrate the two platforms and ensure consistency. The paper answers this question through a demonstration of using Aras Innovator ${ }^{\circledR}$ to build the 
Bill of Material (BoM) of a smart parking system; export Objects' Tree and exchange lifecycle system related information; and using The Open Group standards for IoT to fulfill horizontal interoperability in smart city service systems. The remainder of this paper consists of three sections. Section 2 shades light on the proposed approach of interaction between Lifecycle Systems and IoT platforms; and the main components of this interaction, namely lifecycle management in the smart city context and The Open Group standards. Section 3 demonstrates the interaction between Aras Innovator ${ }^{\circledR}$ and $\mathrm{O}-\mathrm{MI} / \mathrm{O}-\mathrm{DF}$ reference implementation platform for publishing and discovering IoT information. Section 4 includes discussion and future work.

\section{RELATED WORK}

\section{A. Smart City}

According to J. Jin et al. [10] smartness of a city is driven and enabled technologically by the emergent IoT. IoT are the most important data sources for a smart city [11], as illustrated in Fig. 1. Information Sources include IoT sensors deployed in a city environment; city information sources e.g. Open Data portals, city Geographical Information System (GIS) data etc. [12]; and, user generated information through social media e.g. microblogs such as tweets that have been proven feasible for city related event extraction. Information Sinks include IoT Actuators, City Datastores and social media channels through which cities could potentially push information to their citizens.

The Smart City Framework, as proposed by the City Pulse Project [11], consists of number of Functional Groups (FGs). The Large-Scale Data Analysis FG addresses issues related to integration of a large scale of heterogeneous sources producing real-time streams and their semantic enrichment. The Reasoning and Decision Support FG tackles issues related to the ability of the SCF to adapt to alterations based on real-time information streams. It is mainly responsible for monitoring the semantically enriched streams and adapting the collection of stream information from one side and providing an API towards the Smart City Applications from another side. The Large-Scale Analysis and Reasoning and Decision Support functionalities are supported by prior knowledge in the form of the Knowledge Base FG and Reliability and Quality of Information control mechanisms by the Reliable Information Processing FG.

\section{B. The Open Group Standards}

The Open Group standards is one example of IoT interoperability standards. The Open Group standards consist of the Open Messaging Interface (O-MI) and Open Data Format (O-DF) standards [7]. A defining characteristic of $\mathrm{O}$ MI is that nodes may act both as "servers" and as "clients" and therefore communicate with each other or with back-end servers in a peer-to-peer manner. Typical examples of exchanged data are sensor readings, lifecycle events, requests for historical data, notifications, etc. One of the fundamental properties of O-MI is that O-MI/O-DF messages are "protocol agnostic" so they can be exchanged using HTTP, SOAP, SMTP, or similar protocols. O-MI provides a generic Open API for any RESTful IoT information system, meaning that in the same way that HTTP can be used for transporting payloads in formats other than HTML, O-MI can be used for transporting payloads in nearly any format. O-DF is a generic content description model for Objects in the IoT. O-DF is defined as a simple ontology, specified using XML Schema that is generic enough for representing "any" object and information that is needed for information exchange in IoT. ODF is structured as a hierarchy with an "Objects" element as its top element, as depicted in Fig. 2, which can contain any number of "Object" sub-elements.

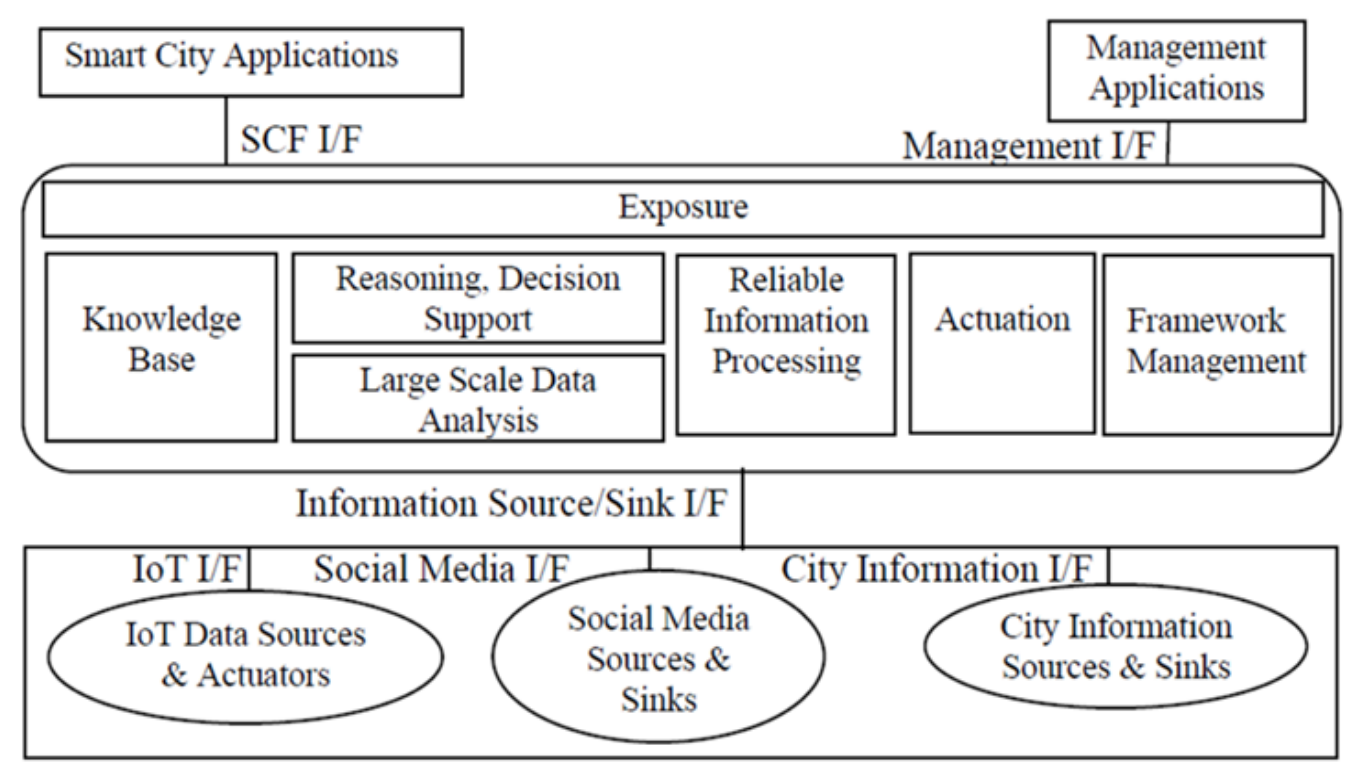

Fig. 1. Smart City Framework [11] 


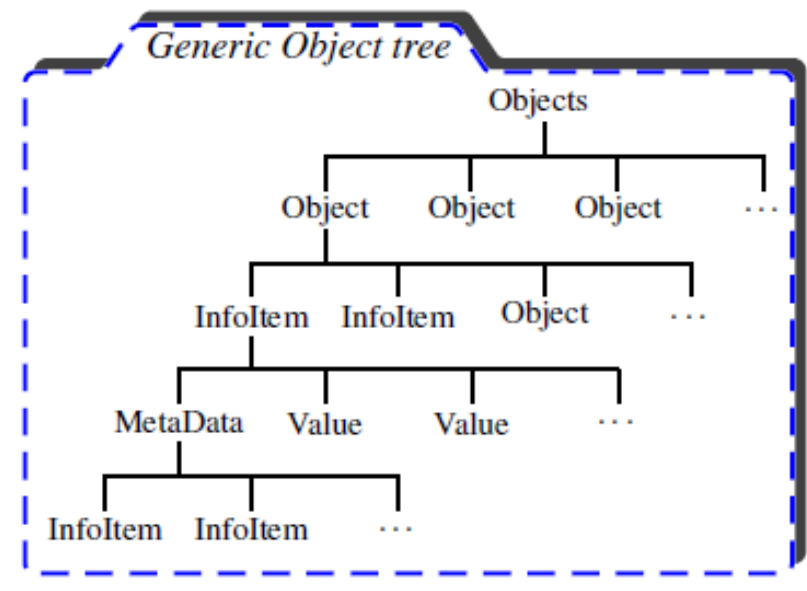

Fig. 2. Open Data Format: generic “Object” tree [20]

\section{Smart City Lifecycle Management (SCLM)}

Lifecycle Management is a concept that evolved in 1990s to improve several engineering aspects of an enterprise to manage its products across their lifecycles [13] [14]. As per J. Li et al., [15], Product Lifecycle Management (PLM) is ideally used to manage the knowledge intensive process. Despite what its name implies, PLM is not only about manufactured products; J. Stark [16] extends the definition of "product" to include services, package of services or a bundle of products and services. O. Isaksson et al. [17] also see "service" as part of the wider concept of "product". Hence, the same definition of "product" can be extended to smart city as a composition of smart objects, smart systems, and smart services that focus on problems and issues that arise in service sectors, like transport, logistics, energy, waste management [18][19]. Accordingly, A. Hefnawy et al. [6][8] have used this analogy to propose lifecycle management approach to be used in the smart city context to manage data, versions, variants and business processes associated with heterogeneous, uniquely identified connected objects.

The vision of applying lifecycle management in the smart city domain(s) is to better integrate people, processes, and systems; and assure information consistency, traceability, and long-term archiving [6]. To achieve such a holistic vision of complete smart city ecosystem, there is a need for interrelated/ interdependent systems to exchange system data that include BOM, versions, variants, stats and other lifecycle related data. In the smart city context, BOM can be defined as the hierarchical structure showing the components that make up the smart city system(s). BOM in the smart city context should allow for loose-coupling, modularity, composability, scalability interdependency and dynamic complexity. During Smart City Lifecycle Management (SCLM) phases, smart city components can be modified or upgraded. Hence, smart city components can have multiple versions, options, variants, releases and alternatives.

\section{INTERACTION APPROACH}

For any particular IoT platform to support data exchange between different IoT objects within a smart system, the IoT platform should be aware of the smart system structure, hierarchy of objects, or what so called "Objects' Tree" or "Bill of Materials". As explained in [6], smart city service systems are featured with structure dynamicity. The structure of components of the smart city can change across different phases of Smart City Lifecycle. System data, versions, variants, processes and other lifecycle related data are also subject to change. From another perspective, in the smart city context, IoT-enabled smart systems are normally interdependent/ interrelated, many of the smart system components are repurposed and the generated information are reused by multiple smart systems. Accordingly, there is a good chance that multiple IoT platforms are involved in one complex smart city system.

Considerations of the Proposed Approach. The approach of this paper was developed considering the following two factors:

- IoT platforms are not the most efficient platforms for building BoM. IoT platforms have very obvious limitations regarding versions, variants, etc. particularly in light of complexity and dynamicity of smart city systems;

- In case of multiple IoT platforms involved in one complex smart city service system, each IoT platform will require to build its own "Objects' Tree"; however, it is the same smart city service system.

The Proposed Approach. The proposed approach consists of the following features, as illustrated in Fig. 3:

- Building smart city service system BoM, using lifecycle management system that is able to exchange system data that include BOM, versions, variants, stats and other lifecycle related data;

- Export smart city service system data in an open standard common payload format, that can be used to build the "Objects" Tree" for IoT platform;

- The proposed approach relies on smart system data exchange between Lifecycle Systems and IoT platforms, instead of embedding lifecycle management within a particular IoT platform. The interaction between lifecycle systems and IoT platforms enables smart system data exchange with multiple open standard IoT platforms, instead of having this data locked to one particular IoT platform. 

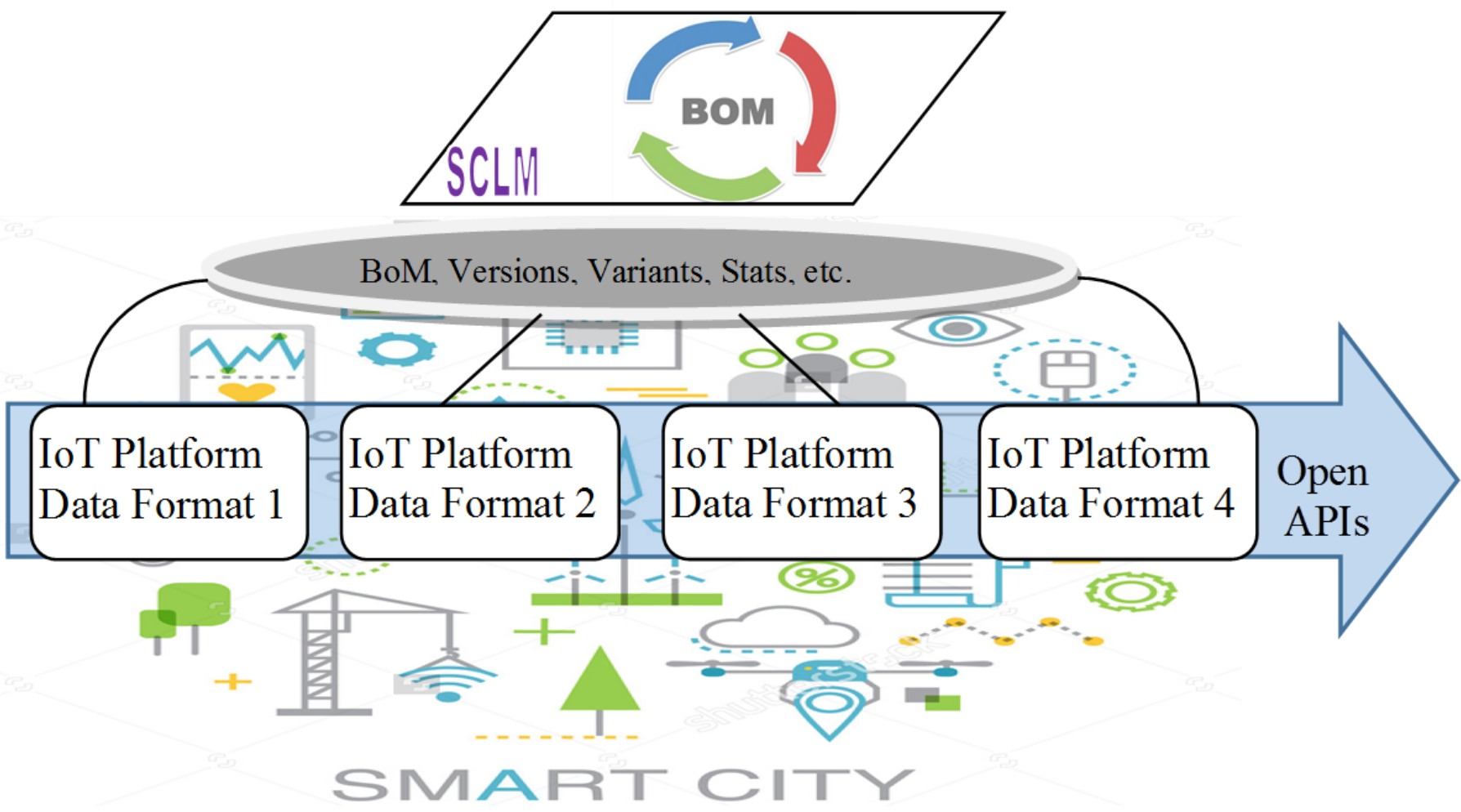

Fig. 3. Interaction between Lifecycle Systems and IoT platforms within Smart City Applications

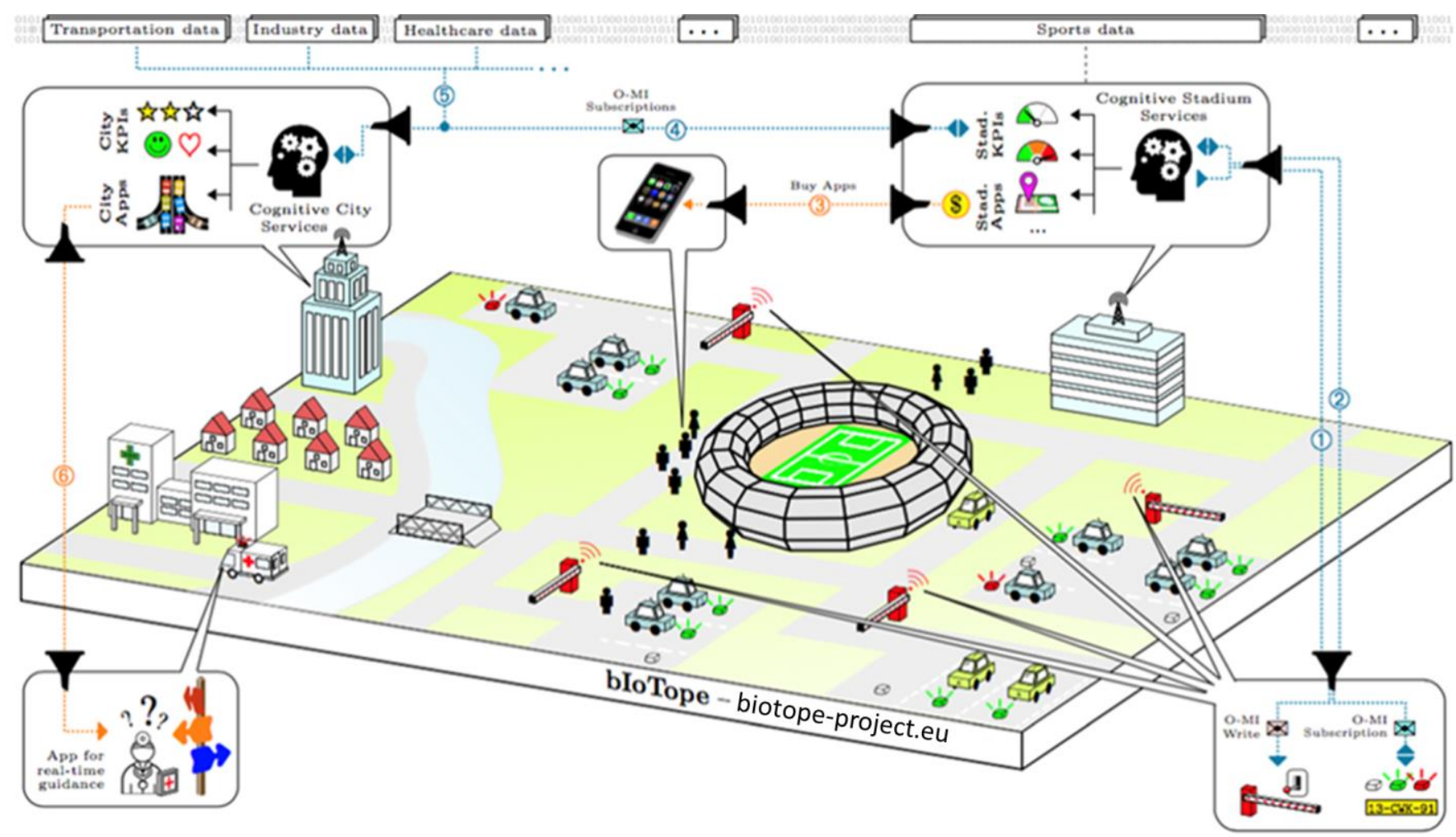

Fig. 4. Smart Parking: High-level Illustration 


\section{INTERACTION BETWEEN ARAS INNOVATOR® AND O- MI/ O-DF REFERENCE IMPLEMENTATION PLATFORM}

This section demonstrates the proposed approach within a smart parking system, as a proof of concept. The smart parking system is developed as a use-case for smart city applications. In this hypothetical scenario, which is detailed in [8], the smart parking is composed of four Parking Areas. Those areas are respectively composed of 3, 6, 3 and 3 parking spots. Each parking area has one Gate and one Gate Plate Number Reader. Each parking spot has unique plate number reader. Fig. 4 illustrates the proposed use-case.

To follow the proposed approach, we have used Aras Innovator ${ }^{\circledR}$ as the lifecycle management system to build the BoM of the smart parking system. For IoT data exchange, we have used O-MI/O-DF Reference Implementation Platform to enable peer-to-peer publication and discovery of parkingrelated information in a more or less aggregated form. Fig. 5 illustrates the Interaction between Aras Innovator ${ }^{\circledR}$ and $\mathrm{O}$ MI/O-DF Reference Implementation Platform.

Smart Parking System Bill-of-Materials (BoM). To build smart parking system BoM, we had to change the standard data model of Aras Innovator® to support the smart parking system components. We started by breaking down the smart parking system into components and identifying its parts and assemblies. Then, we grouped these components in sets of families that were used later as "Classifications". We identified two main families, smart components that refer to sensors and actuators, in our case, Plate Number Readers and Gates; and, the assemblies that refer to Parking Zones and other elements used to structure the BOM sub-assemblies. Specific attributes can be then added for each classification. Once the data model is defined, the BOM can be built and entered in Aras Innovator ${ }^{\circledR}$ following the hierarchical structure that describes smart parking system components while using the proper classification at each level. Fig. 6 is a screenshot from Aras Innovator®, showing the user interface for smart parking system.

BOM Transformation to O-DF. To transform BOM to O-DF, we started by creating a library of classes corresponding to the O-DF XSD schema released by The Open Group [9]. This library was used in Aras Innovator ${ }^{\circledR}$ to export the O-DF tree payload in XML or JSON. Algorithm 1. is the recursive procedure used to convert the $\mathrm{BOM}$ into $\mathrm{O}-\mathrm{DF}$ using the classification defined in the data model.

The classification eases the differentiation of the assemblies and smart components in the BOM, giving each one the right XML tag according to the O-DF standard. Assemblies generate "Object" tags with the associated element "id", while the smart items generate "InfoItem" tags with an attribute corresponding to the "name". Additional properties and metadata can be also exported if defined. Fig. 7. shows the result of the transformation of the BOM to the O-DF tree with a highlight of zones 1 and 2 of the smart parking.

Export from Aras Innovator ${ }^{\circledR}$ to O-MI/O-DF Reference Implementation Platform. To ensure communication between Aras Innovator ${ }^{\circledR}$ and O-MI/O-DF Platform, two ways are proposed in this proof of concept. The first trivial solution is based on a simple exchange of XML files by exporting the $\mathrm{O}$ DF tree using the button marked " 1 " in Fig. 8. The second solution is more elaborated and uses an API that we have developed to consume any SOAP or RESTful web services directly from the Aras Innovator ${ }^{\circledR}$. This solution implies that the O-MI/O-DF Platform must expose a proper web service that handles the O-DF Objects' Tree. Then, the export can be done by a simple click on the button marked "2" in Fig. 8.

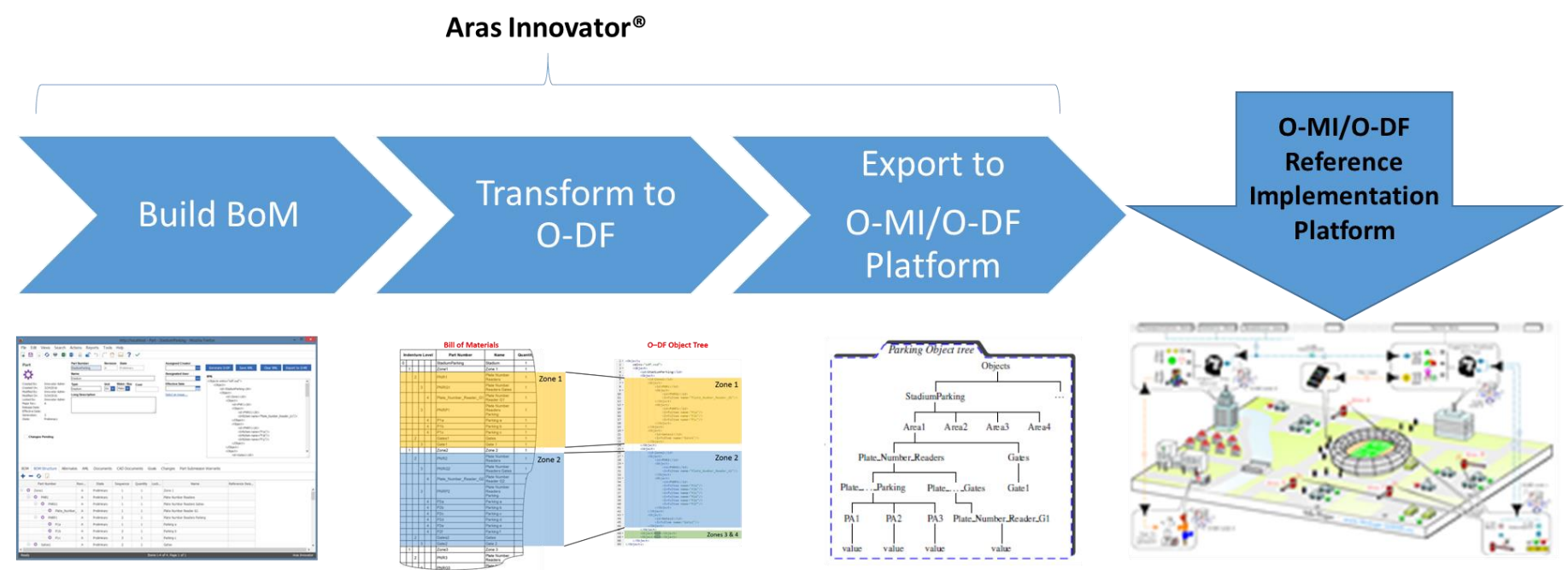

Fig. 5. Interaction between Aras Innovator ${ }^{\circledR}$ and O-MI/O-DF Reference Implementation Platform within Smart Parking 


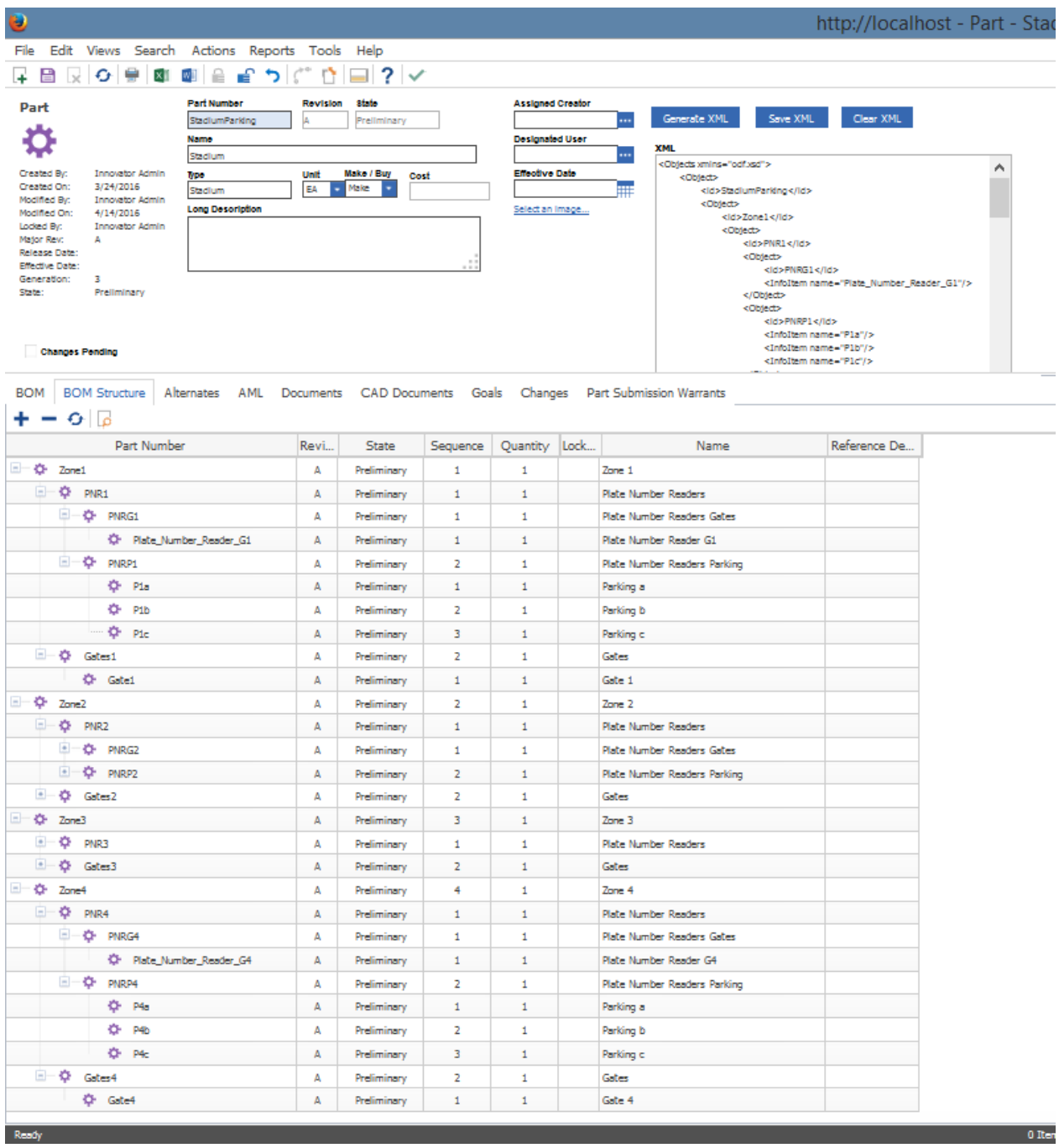

Fig. 6. BOM: Screenshot from Aras Innovator®

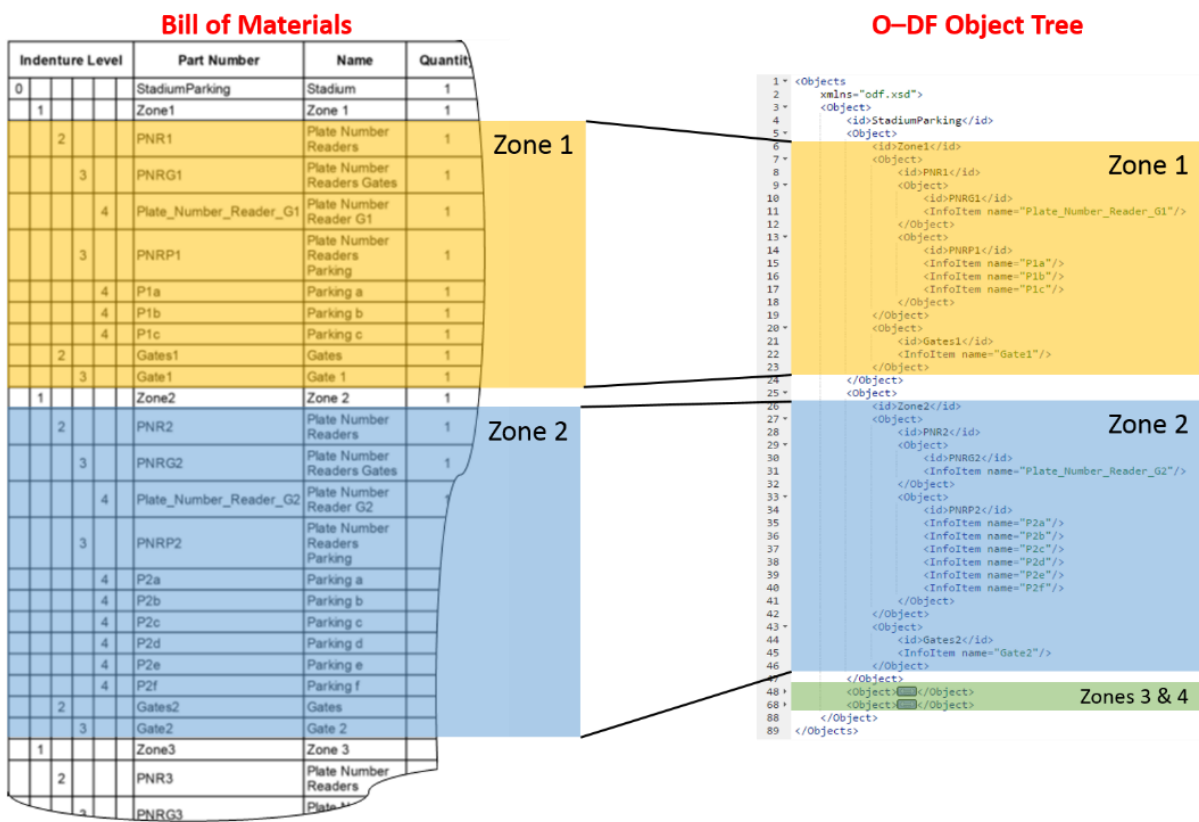

Fig. 7. BOM Export to O-DF Object Tree 

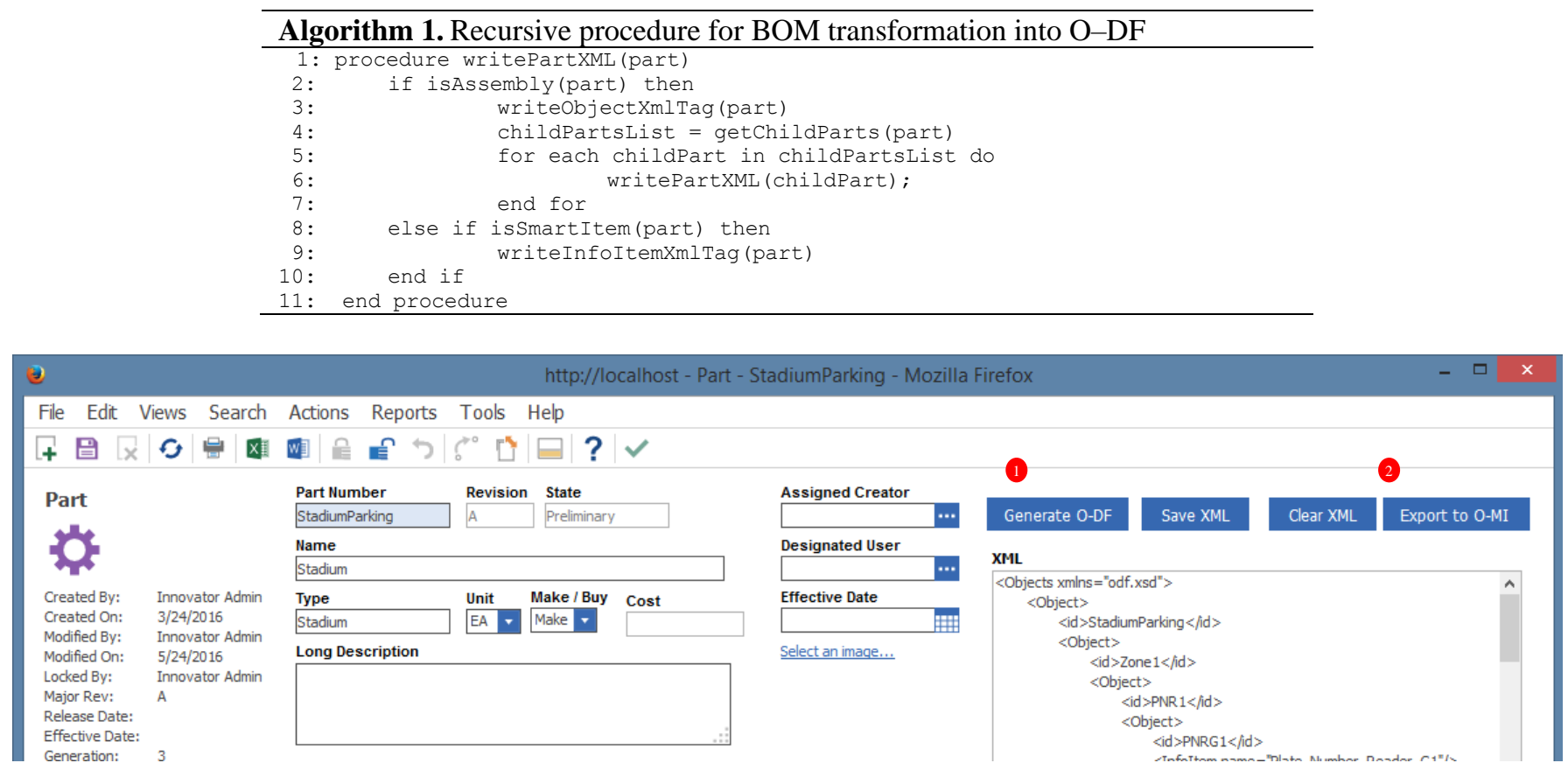

Fig. 8. Smart Parking part form in Aras Innovator ${ }^{\circledR}$

\section{RELEVANCE OF LIFECYCLE Management to SMaRt City}

To evaluate the proposed interaction approach and generally the relevance of lifecycle management to smart city, we conducted systematic interviews with a representing sample of stakeholders from selected case studies. Part of the interview intended to identify issues and threats in smart cities and to evaluate the impact of the identified smart city issues and concerns. To better understand the level of threat of each of the identified issues and concerns, we have requested interviewees to weigh the level of threat on a scale from 0 to 10. On a similar scale, we have requested interviewees to weigh the relevance of lifecycle management to address each of the identified concerns and issues. The level of threat of identified issues and the strength of relevance of lifecycle management are both based on stakeholder opinions. To ensure better quality of opinions, we used to brief stakeholders about the previous work of smart city lifecycle management. Figure 9 shows two mapped radar style graphs. The first graph is an aggregated demonstration of the level of threat of each issue/ concern, according to the feedback received from participant stakeholders. The second graph shows the relevance of lifecycle management to address these concerns and issues.

\section{DISCUSSION AND FUTURE WORK}

To ensure interoperability between IoT-enabled smart city systems, there is a need for two types of data to be exchanged. First, data collected from heterogeneous IoT data sources that can be used in different domains. Second, system data, versions, variants, processes and other lifecycle related data. This paper proposes building smart city service system BoM, using lifecycle management system; then, export smart city service system data in an open standard common payload format, that can be used to build the "Objects" Tree" for IoT platform. To ensure full integration, interaction between lifecycle systems and IoT platforms is proposed to enable smart system data exchange with one or more open standard IoT platforms. The proposed approach is demonstrated within a smart parking use-case, where Aras Innovator ${ }^{\circledR}$ is used to build the Bill of Material (BoM) of a smart parking system; export Objects' Tree and exchange lifecycle system related information; and O-MI/O-DF Reference Implementation Platform is used to enable peer-to-peer publication and discovery of parking-related information.

This paper presents the interaction between Aras Innovator®, as the lifecycle management system, and O-MI/O-DF Reference Implementation Platform, as a single open standard IoT platform. The proposed future work is to extend the usecase to include the proposed approach between multiple interdependent smart city systems that use different open standard IoT platforms; hence, to examine the interaction between the lifecycle management system and multiple open standard IoT platforms. 


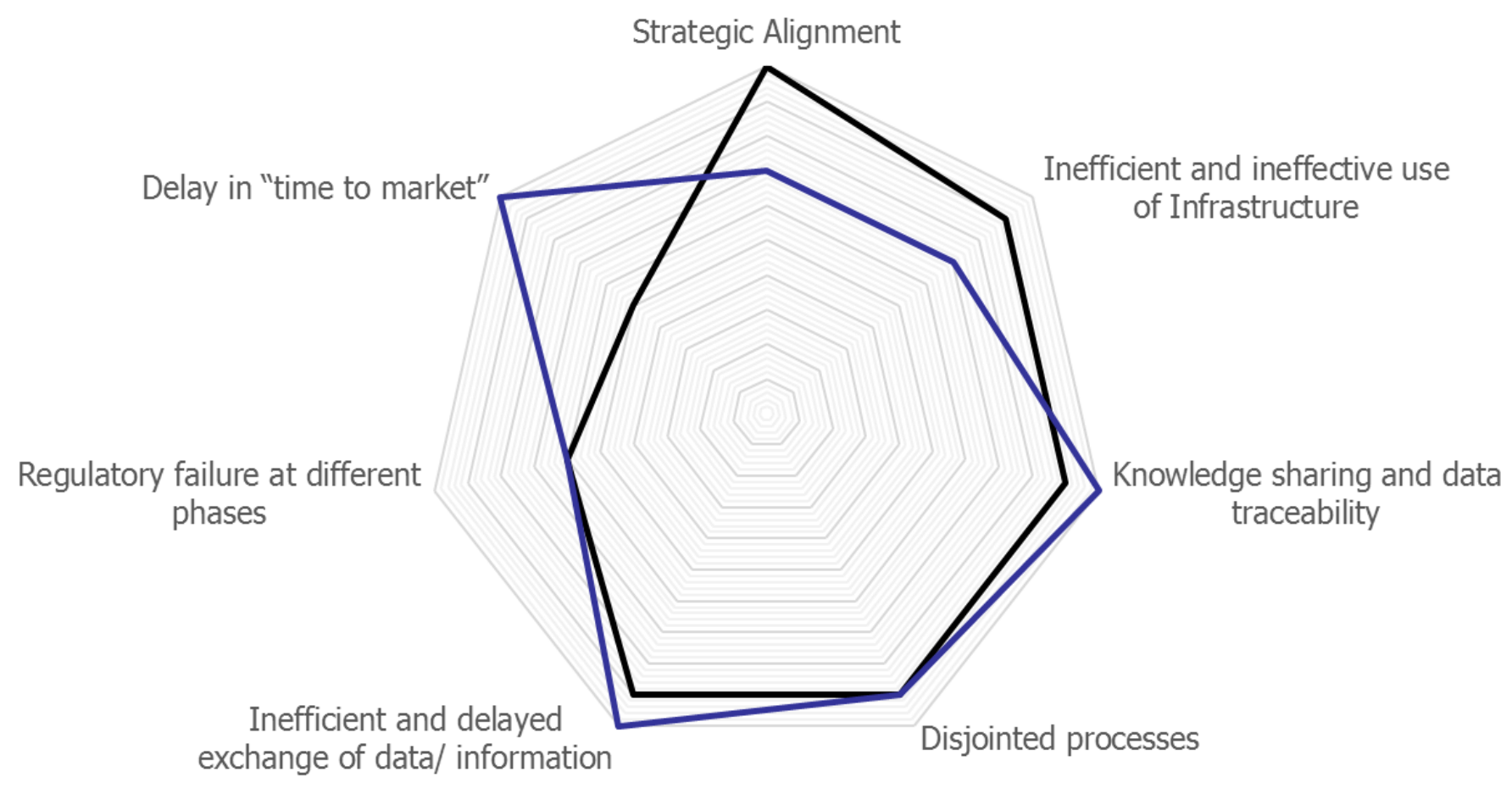

口Issue/ Concern $\mathbf{Q}$ Lifecycle Management Relevance

Fig. 9. Relevance of Lifecycle Management to Smart City Concerns 


\section{REFERENCES}

[1] I. I. Initiative. "Towards a definition of the Internet of Things". IEEE IoT Initiative white paper, 2015.

[2] AIOTI. "Alliance for Internet of Things Innovation". European Commission, 2015.

[3] D. Raggett. "The Web of Things: Challenges and opportunities". Computer, no. 5, pp. 26-32, 2015.

[4] J. Swetina, G. Lu, P. Jacobs, F. Ennesser, and J. Song. "Toward a standardized common M2M service layer platform: Introduction to OneM2M". IEEE Wireless Communications, vol. 21, no. 3, pp. 20-26, 2014.

[5] The Open Group. "The Nexus of Forces in Action Business Use-Cases of Open Platform 3.0TM". Open Platform 3.0 initiative white paper, 2014.

[6] A. Hefnawy, et al. "Lifecycle Management in the Smart City Context: Smart Parking Use-Case". The 13th IFIP PLM16 International Conference, Columbia 11-13 July, 2016.

[7] K. Främling, S. Kubler, A. Buda. "Universal Messaging Standards for the IoT from a Lifecycle Management Perspective". IEEE Internet of Things Journal, Volume 1, Issue 4, Page 319 - 327. 2014.

[8] A. Hefnawy, A. Bouras and C. Cherifi. "IoT for Smart City Services: Lifecycle Approach". The International Conference on Internet of things and Cloud Computing (ICC 2016), Cambridge 22-23 March 2016.

[9] The Open Group. Open Data Format (O-DF), an Open Group Internet of Things (IoT) Standard. October 2014. Available at www.opengroup.org/bookstore/catalog/c14a.htm. US ISBN 1-937218-59-1.

[10] J. Jin, J. Gubbi, S. Marusic, M. Palaniswami. "An Information Framework for Creating a Smart City through Internet of Things". IEEE Internet of Things Journal, Vol. 1, No. 2, April 2014.

[11] V. Tsiatsis (editor), et.al. "Real-Time IoT Stream Processing and Large-scale Data Analytics for Smart City Applications". EU FP7 CityPulse, Deliverable D5.1, 2014.
[12] A. Medvedev, P. Fedchenkov, A. Zaslavsky, T. Anagnostopoulos, S. Khoruzhnikov. "Waste management as an IoT enabled service in Smart Cities". $8^{\text {th }}$ International Conference on Internet of Things and Smart Spaces, ruSMART 2015, St. Petersburg, Russia. August 2015.

[13] H. Zhang, A. Sekhari, Y. Ouzrout, A. Bouras. "PLM components monitoring framework for SMEs based on a PLM maturity model and FAHP methodology" Journal of Modern Project Management, Volume 2. N${ }^{\circ}$, Pages 109-119, 2014.

[14] H. Zhang, Y. Ouzrout, A. Bouras, M. Savino. "Sustainability consideration within Product Lifecycle Management through Maturity Models Analysis". Int. J. Services and Operations Management. Volume 19, Issue 2. 2014.

[15] J. Li, F. Tao, Ying Cheng, L. Zhao. "Big Data in product lifecycle management". International Journal Advanced Manufacturing Technologies, Volume 81, Issue 1, Pages 667684. 2015

[16] J. Stark. "Product Lifecycle Management: 21 century paradigm for product realization”. 2nd edition. 2011.

[17] O. Isaksson, T.C. Larsson and A. Öhrwall Rönnbäck. "Development of Product-Service Systems: Challenges and Opportunities for the Manufacturing Firm". Journal of Engineering Design; Special Issue on Product-Service Systems; Volume 20, Issue 4, pages 329-348, 2009.

[18] S. Cavalieri, G. Pezzotta. "Product-Service Systems Engineering: State of the art and research challenges". Computers in Industry, Volume 63, Issue 4, Pages 278-288, May 2012.

[19] J. Poncela, et al. "Smart Cities via Data Aggregation". Wireless Personal Communications. Volume 76, Issue 2, pp 149-168. May 2014.

[20] S. Kubler, J. Robert, A. Hefnawy, A. Bouras and C. Cherifi, K. Främling. (2016) 'IoT-based Smart Parking System for Sporting Event Management', in proceedings of the 13th Annual International Conference on Mobile and Ubiquitous Systems: Computing, Networking and Services. November 28 - December 1, 2016. Hiroshima, Japan. 